\title{
The effect of a structured internship on the clinical performance of novice nurses?
}

\author{
J ames Whyte IV ${ }^{1}$, Roxanne Hauber ${ }^{1}$, Paul Ward ${ }^{2}$ \\ 1. Florida State University, Tallahassee, United States. 2. University of Greenwich, London, United Kingdom. \\ Correspondence: James Whyte IV. Address: Florida State University, Tallahassee, United States. \\ Email: jwhyte@fsu.edu
}

Received: May 26, 2014

Accepted: August 31, $2014 \quad$ Online Published: September 11, 2014

DOI : $10.5430 /$ jnep.v4n11p74

URL: http://dx.doi.org/10.5430/jnep.v4n11p74

\section{Abstract}

Objective: The study examined the clinical performance differences of novices before and after a critical care internship and compare their performance attributes to a reference group comprised of experienced critical care nurses. The extant research regarding clinical internship programs has focused on retention in practice, workforce issues and competence. While studies have shown a pattern of improved retention in practice settings, they have failed to objectively measure actual clinical performance.

Methods: The study design was based on pre-post comparisons of novice nurses and a reference group comprised of experienced nurses who served as a benchmark. The novice group was required to respond to patient needs in high-fidelity clinical scenarios before and after an internship. The experienced nurses attended a single testing session.

Results: Findings revealed statistically significant improvement in the performance of the novice group; however, they failed to perform at the level of the experienced nurses.

Conclusions: The study is the first to detail the degree to which a structured internship can facilitate changes in selected aspects of clinical performance. The study establishes the effect associated with engagement in a structured internship. While novices improve significantly, they fail to achieve the level of clinical performance seen in experienced nurses. The paper will present background information related to the established effects of internship programs, and will then present the data related to the current study. The paper will then present similarities and differences between the results of the current study, and the literature.

\section{Key words}

Internships, Residency programs, Clinical competence, Novice nurses, Simulation

\section{I ntroduction}

In recent decades, healthcare practice has become progressively more complex, thus placing extensive demands on healthcare workers across disciplines and requiring the institution of initiatives directed towards increasing the quality of care $^{[1]}$. When the dynamics interjected by the aging workforce is taken into consideration, it becomes clear that strategies to speed the professional development of new nurses entering the workforce to replace those nearing retirement are essential ${ }^{[2]}$. This has resulted in the proliferation of a variety of residency and internship programs designed to provide rich 
learning experiences that accelerate the preparation of nurses to practice in highly-complex practice settings ${ }^{[3]}$. These programs integrate guided clinical practice and academic exercises such as case studies and simulation in ways that bridges academic and clinical practice environments ${ }^{[4]}$. Despite a variety of initiatives aimed at improving the knowledge, skills, and attitudes required for nursing in the $21^{\text {st }}$ century, nurses and nurse executives continue to report a lack of preparedness related to the highly technical aspects of practice. This highlights specific learning needs, especially for nurses who are new to practice ${ }^{[5]}$. While the goal of most internship and residency programs is to prepare nurses adequately for practice, to date there has been a dearth of studies that have quantified the effects of internship programs on nurses' performance ${ }^{[6]}$.

\section{Background}

Initial review and consideration of the extant literature indicated that there were few studies that provided objective measurement of nursing performance that reflected upon the effects of internship experiences. There were, however, a variety of studies that reflected upon aspects of the effects of nursing internships. A variety of studies investigate the effect of residency and internship programs on nursing workforce related issues. These studies are important since they provide the fiscal justification for such programs. Austerity in health-related programming at the governmental level demands the development of means to decrease cost. Studies have focused on aspects of nursing workforce issues. It is important to consider that internship programs are ideally suited for novice nurses. Novice nurses attending residency programs tend to place great value on aspects of professional socialization, as compared to more experienced nurses, and lack the depth of experience of their longer serving counterparts ${ }^{[7]}$. Many of these studies have established the effect of residency programs on the recruitment and retention of nurses ${ }^{[8-11]}$, rather than on their clinical performance attributes.

The second area of study addresses the effect of these training experiences on competence in clinical practice. The measurement of competence is complex, since the behaviors that comprise a competent practitioner (e.g., performance on low frequency cases; triage in cases where diagnostic information is limited or absent, uncertainty is high, and the patient condition is highly dynamic) are often difficult to observe or quantify in naturalistic settings. Establishing the effect of internship or residency programs on competence presents some interesting challenges. Early studies in the area focused on the degree to which internship programs improved knowledge levels and various perceptive variables related to a particular setting ${ }^{[12,13]}$. Often, studies have been based upon methods that did not directly measure observable aspects of nurse performance, and instead focused on the use of questionnaires and peer rating ${ }^{[14-16]}$. While these studies are of value, they do not directly clarify measureable influences on nurse performance. Other studies have focused on interpersonal variables, such as improvements in confidence ${ }^{[12,17,18]}$ or decreased experiences of stress following program attendance $^{[19,20]}$. To date, no published study has directly measured the effects of a nurse internship/residency experience on the performance of nurses who receive such training.

It is important to examine the measurement of nursing performance in order to properly lay the foundation for the analysis that comes later in this paper. The current paper focuses on nurses' ability to achieve physiologic stability during the scenarios used in the study. Ericsson, Whyte and Ward, in their seminal review, highlighted inconsistencies in the measurement of nurse performance in studies designed to determine their level of expertise ${ }^{[21]}$. They found that, invariably, many studies focused on facts such as subjective ratings, peer nomination and a variety of scored instruments designed to measure performance. More recently, researchers using the Expert Performance Approach ${ }^{[21]}$ began to develop measurement strategies that focused on the identification of objective measures ${ }^{[23-26]}$. These studies focus primarily on two forms of objective measurement. The first is the coding of nursing actions in the simulated task environment using precise task analysis and multiple coders with verification. The second, perhaps even more objective method is the use of physiologic variables to confirm the effect (positive or negative) of nursing actions ${ }^{[23]}$. For the current study, physiologic variables were the focus of our efforts to objectively measure nursing performance.

The purpose of the present study was to examine the ability to manage physiologic stability in novices before and after a critical care internship, and compare their performance attributes to a reference group comprised of experienced critical 
care nurses. Using this approach, our goal was to describe the degree of change in competency associated with engagement in the internship experience, and to compare the direction and magnitude of the expected improvement relative to exemplar performance of experienced nurses. The study was based upon the Expert Performance Approach (EPA) ${ }^{[21]}$. According to the EPA it is desirable to determine performance based upon tasks with sufficient complexity that differences in performance materialize. While a variety of tasks were completed during the scenarios, the titration of vasoactive medications, as the key action in determining patient stability in the scenarios, was chosen. The research questions and hypothesis for the study follow. For the hypothesis, $\mu_{1}$ is the mean physiologic score for the pre-test novice group, $\mu_{2}$ is the mean physiologic score for the post-test novice, and $\mu_{3}$ is the mean physiologic score for the experienced group.

1) What is effect of a structured internship on novice nurses' ability to manage physiologic stability in a critical care based simulated task environment? We hypothesize that engagement in the structured internship will enhance participant's ability to manage physiologic instability $\left(H_{0}: \mu_{1}=\mu_{2} ; H_{1}: \mu_{2}>\mu_{1}\right)$

2) What is difference between novice (pre and post internship) and experienced nurses' ability to manage physiologic stability in a critical care based simulated task environment? We hypothesize that novices will improve with regards to the performance of the experienced nurses. Further, we hypothesize that nurse performance will not improve to levels greater than those seen in the experienced nurses. $\left(H_{0}: \mu_{1}=\mu_{3} ; H_{0}: \mu_{2}=\right.$ $\left.\mu_{3} ; H_{1}: \mu_{1}<\mu_{2}, H_{2}: \mu_{2}<\mu_{2}\right)$

\section{Methods}

The study used testing in a simulated task environment to measure novice and experienced nurses ability to manage physiologic instability. The study was based on a pre-post comparison of novice nurses and a reference group comprised of experienced nurses. The reference group was included in the study in order to serve as a benchmark of the desired level of practice in critical care nurses. A pre-test post-test design was implemented in the novices before and after engagement in a structured 4-week internship in a critical care setting. Experienced nurses attended a single session in the simulated task environment, and were to act as a benchmark group.

Participants were recruited from a class of 88 graduating nursing students who attended a five-semester baccalaureatenursing program, and entering practice in a critical care setting. All of the novice participants attended a critical care based internship as a condition of their participation. The reference group was comprised of ten experienced nurses who were actively practicing in critical care units at the time that the study was conducted. The study was approved by the university Human Subjects Committee, and all participants were volunteers from whom Informed consent was acquired.

Testing was conducted in a simulation laboratory that included a patient-care suite that was configured and equipped like a typical room in a standard intensive care unit. A METI ECS adult model ${ }^{\circledR}$ simulator served as the simulated patient. The laboratory was wired for sound and included video monitoring ( 4 angle) for ease of observation. The study focused on the ability of participants to manage the physiologic integrity of the manikin. Thus, the simulator was configured to measure physiologic variables at 5-second intervals. Concurrently Microsoft Excel ${ }^{\mathrm{TM}}$ was configured to harvest and collate physiologic data following each testing session. In this way, the ability to attain beneficial outcomes was stressed above specific actions taken in the simulated task environment.

\subsection{Data collection}

Four scenarios were developed for use in the simulation protocol, each concentrated around a well-delineated clinical problem, so that performance could be operationally defined and measured: 1) A patient with sepsis and hypotension who is being treated with a dopamine infusion; 2) A patient being treated for atrial fibrillation with rapid ventricular response who is suffering a bout of tachycardia despite an infusion of diltiazem; 3) A patient with refractory hypotension and fluid 
volume contraction who is being treated with a norepinephrine infusion; 4) A patient being treated for a hypertensive emergency who is experiencing hypotension due to the administration of excessive sodium nitroprusside.

Each scenario was five minutes in length. This time interval was selected based upon experience from previous studies performed in the lab, and out of concern that long scenarios often allowed the scenario to progress to the point that participant data were not comparable. The scenarios were initially developed based on input from two experts in critical care nursing. They were then trialed using three novice and three experienced nurses. Each of these participants provided input on the scenarios, which the original developers used to further refine the scenarios. The scenarios were then piloted using three additional experienced nurses, who also provided input on the scenarios.

Each of the scenarios required the participant to administer care to a patient with various degrees of cardiovascular and respiratory compromise. Participants were asked to respond to the scenarios just as they would in an actual hospital setting.

The novice group was tested on each of the four scenarios one week before and within 10 days of completing a four -week internship program. The 26 novices completed their internship in critical care under the direction of highly experienced preceptors. The internship was comprised of 160 hours of clinical experience that included the completion of a variety of critical care tasks, including the administration and titration of vasoactive medications. Additionally, the novices continued to attend didactic coursework throughout the internship period. The novice group was initially exposed to the scenarios in order $(1,2,3,4)$ for the pretest, and in a different order $(2,3,4,1)$ on the post-test. This approach was undertaken to avoid habituation.

The group of experienced nurses was tested once on all four of the test-scenarios within the same timeframe as the student nurses. The scenarios were administered to the experienced nurses in the order that they were given to the novices during the pre-test. The primary data source was the capture of simulator vital signs at 5-second intervals throughout the scenarios. These data were captured and uploaded immediately to Microsoft Excel TM for analysis.

\subsection{Analysis}

Data analysis for the study focused on reflecting the physiologic status of the simulator. A Microsoft Excel тм file comprised of the simulator's physiologic variables was compiled. The primary focus was on blood pressure management due to its direct relationship to vasoactive medications (scenarios 1, 3,4) and in the case of scenario 2, heart rate was the primary dependent variable. Heart rate was selected as the dependent variable for scenario 2 due to the direct effect of Diltiazem on heart rate. Additionally, the analysis included the time of initial titration of the vasoactive medications, in order to provide a link between actions and physiologic effects.

\section{Results}

\section{The participants}

The novice group included 26 participants. There were 22 females and 4 four males; 18 White (69.2\%), four African American (15.3\%), and 4 four Hispanic (15.3\%) participants in this group and their mean age was 22.8 (SD 1.24) years. The experienced nurse group included eight females and two males, with eight white (80\%) one Hispanic (10\%) and one African American (10\%) participant. The mean age of experienced nurses was 48 (SD 9.63), with a mean of 17.25 (SD 7.61) years of experience.

Results of Research Question-1: What is effect of a structured internship on novice nurses' ability to manage physiologic stability in a critical care based simulated task environment?

Table 1 reports the pre- and post-test scores for the initiation of titration of vasoactive medications. While a variety of other actions occurred during the scenarios, the decision to titrate represents the single most effective means of managing the 
physiologic instability present in the scenarios. Additionally, it is essential that nurses appreciate stimuli within the simulated task environment. The effect sizes reported in this table indicate a medium-sized effect related to the participants engagement in practice-related activities during the internship experience.

Table 1. Comparison of novice initiation of titration on pre and post-test scenarios including effect sizes $(\mathrm{N}=26$, variables listed in seconds)

\begin{tabular}{|c|c|c|c|}
\hline & $\begin{array}{l}\text { Pretest-Time } \\
\text { titration Initiated }\end{array}$ & $\begin{array}{l}\text { Post-test-Time } \\
\text { titration initiated }\end{array}$ & t-score \\
\hline Scenario-1 & 293.08 (SD 12.24) & $\begin{array}{l}236.69(\mathrm{SD} 60.74) \\
\text { ES } 0.58\end{array}$ & $5.315^{* *}$ \\
\hline Scenario-2 & 295.12 (SD 17.42) & $\begin{array}{l}229.65(\mathrm{SD} 66.50) \\
\text { ES } 0.56\end{array}$ & $5.006 * *$ \\
\hline Scenario-3 & $293.5($ SD 20.22) & $\begin{array}{l}211.42(\text { SD } 69.09) \\
\text { ES } 0.63\end{array}$ & $6.477 * *$ \\
\hline Scenario-4 & $290.00($ SD 32.73) & $\begin{array}{l}211.58(\text { SD } 75.99) \\
\text { ES } 0.56\end{array}$ & $5.516^{* *}$ \\
\hline
\end{tabular}

$* p<.05 ; * * p<.001$.

Table 2, in a manner similar to the data presented in Table 1, provides a reflection of the pre and post-test physiologic parameters. Data regarding physiologic parameters was captured in five-second intervals throughout the scenario. This provided a direct reflection of the outcomes of care for the participants. In scenarios 1, 3 and 4 , the primary parameter that was influenced by the participant's engagement in titration was mean arterial blood pressure. In scenario-2, the primary physiologic parameter influenced by the participant was pulse rate. The results show statistically significant improvement in physiologic stability across the scenarios. The effect sizes, as well, indicated a medium-size effect on the novice participant's ability to positively influence physiology associated with the internship experience.

Table 2. Comparison of novice performance related to physiologic parameters on pre and post-test scenarios including effect sizes $(\mathrm{N}=26)$

\begin{tabular}{|c|c|c|c|c|c|}
\hline & Pretest pulse & Post-test pulse & Pretest MABP & Post-test MABP & $t$-Score \\
\hline Scenario-1 & $\mathrm{n} / \mathrm{a}$ & $\mathrm{n} / \mathrm{a}$ & $\begin{array}{l}51.89 \\
(\mathrm{SD} .34)\end{array}$ & $\begin{array}{l}60.92 \\
(\mathrm{SD} 7.91) \text { ES } 0.63\end{array}$ & $-5.810 * *$ \\
\hline Scenario-2 & $\begin{array}{l}173.08 \\
(\mathrm{SD} 24.57)\end{array}$ & $\begin{array}{l}126.36(\mathrm{SD} 44.80) \\
\mathrm{ES} 0.54\end{array}$ & $\mathrm{n} / \mathrm{a}$ & $\mathrm{n} / \mathrm{a}$ & $4.184 * *$ \\
\hline Scenario-3 & $\mathrm{n} / \mathrm{a}$ & $\mathrm{n} / \mathrm{a}$ & $\begin{array}{l}51.82 \\
(\mathrm{SD} 2.47)\end{array}$ & $\begin{array}{l}57.95 \\
(\mathrm{SD} 5.07) \text { ES } 0.61\end{array}$ & $-6.324 * *$ \\
\hline Scenario-4 & $\mathrm{n} / \mathrm{a}$ & $\mathrm{n} / \mathrm{a}$ & $58.16(\mathrm{SD} 4.83)$ & $\begin{array}{l}65.15(\mathrm{SD} 7.46) \\
\mathrm{ES} 0.49\end{array}$ & $-4.804 * *$ \\
\hline
\end{tabular}

${ }^{*} p<.05 ; * * p<.001 ;$ MABP $=$ Mean Arterial Blood Pressure

\section{Results for research question-2: What is difference in novice (pre and post internship) and experienced nurses' ability to manage physiologic stability in a critical care based simulated task environment?}

The study, as previously described, used a highly experienced reference group that represented a benchmark for the purpose of making comparisons between the groups. Table 3 provides comparison of physiologic outcomes when comparing the groups. Comparison of the novices to the experienced benchmark group reveals a pattern of superior performance by the experienced nurses in comparison to the novices. Across all four scenarios, the pre-test novices were significantly less able to maintain the physiologic parameters $(P<.001)$. The post-test comparison however, demonstrates a narrowing of these performance differences. That is, the novices, while lagging behind the experienced group, were able to achieve physiologic stability to a greater degree. 


\section{Discussion}

This section will be presented according to the research questions for the study.

\section{Research Question-1: What is effect of a structured internship on novice nurses' ability to manage physiologic stability in a critical care based simulated task environment?}

During the analysis, it was clear that the novices were having difficulty associated with determining the point at which titration was indicated. This trend appeared to be secondary to their difficulty in identifying task relevant cues within the simulated task environment and acting upon them. Because of this trend, the initial analysis examined the ability of the novice participants to progress to the point that they engaged in titrations that were required to positively influence the patient's physiologic condition. Table 1 reflects a statistically significant trend $(p<.05)$ in each of the scenarios that suggest a relationship between the internship experience and improved speed of response. Table 2 reflects the corresponding improvement in physiologic parameters (Pulse and Blood Pressure) associated with the initiation of the titration action. There appears then, to be two areas of improvement in performance as a result of the internship experience: 1) speed of response and 2) accuracy of action. In acquiring the ability to act earlier, novices may have done so due to increased confidence, which is consistent with past studies ${ }^{[12,17,18]}$. Further, the findings may also indicate the advantages of deliberate practice with continuous feedback from a preceptor over a period of time. To date, however, this is the first study that directly quantified these improvements in novice nurses.

\section{Research question-2: What is difference in novice (pre and post internship) and experienced nurses' ability to manage physiologic stability in a critical care based simulated task environment?}

In a basic sense, this component of the study determined the relationship of novice nurses ability to stabilize the physiology of decompensating simulated patients, compared to the performance of experienced critical care nurses.

The data addressing this research question was perhaps the most significant. Table 3 provided details regarding the time to titration by the control group (experienced nurses) and the novices. At pretest, there is a wide gap between the performance of the two groups, with novices displaying a clearly diminished ability to process task relevant cues and engage in the titration tasks at an acceptable rate. When one compares the post internship scores, a marked narrowing between novice and expert is apparent. While the novices improve, however, they fail to perform at the level of the experienced nurses even after their internship experience. Table 3 examined the differences in physiology while performing the same group comparisons. The pretest comparison reveals the failure of the novices to stabilize the patients across the trials $(P<.05)$. While the novices continue to lag following the internship experience, they do achieve acceptable levels of physiologic stability following the internship experience. This reflects a trend whereby the novices, following the internship experience, have progressed to the point that they can achieve a minimal level of physiologic stability in their patients receiving vasoactive medications.

Table 3. Comparison of physiologic parameters, novice versus experienced control group

\begin{tabular}{|c|c|c|c|c|c|}
\hline & $\begin{array}{l}\text { Experienced } \\
(\mathrm{N}=10)\end{array}$ & $\begin{array}{l}\text { Novice Pre-test } \\
(\mathrm{N}=26)\end{array}$ & $\begin{array}{l}T \text {-score (pretest } \\
\text { comparison) }\end{array}$ & $\begin{array}{l}\text { Novice Post-test } \\
(\mathrm{N}=26)\end{array}$ & $\begin{array}{l}T \text {-Score } \\
\text { (post-test comparison) }\end{array}$ \\
\hline $\begin{array}{l}\text { Scenario-1 } \\
\text { (MABP) }\end{array}$ & $\begin{array}{l}66.13 \\
(\mathrm{SD} 4.92)\end{array}$ & $\begin{array}{l}51.89 \\
(\mathrm{SD} .34)\end{array}$ & $15.012 * *$ & $\begin{array}{l}60.92 \\
(\mathrm{SD} 7.91)\end{array}$ & 1.934 \\
\hline $\begin{array}{l}\text { Scenario-2 } \\
\text { (Pulse) }\end{array}$ & $\begin{array}{l}86.00 \\
(\mathrm{SD} 35.76)\end{array}$ & $\begin{array}{l}173.08 \\
(\mathrm{SD} 24.57)\end{array}$ & $-3.036 * *$ & $\begin{array}{l}126.36 \\
(\mathrm{SD} 44.80)\end{array}$ & -1.586 \\
\hline Scenario-3 (MABP) & $\begin{array}{l}70.63 \\
(\mathrm{SD} 2.1)\end{array}$ & $\begin{array}{l}51.82 \\
(\mathrm{SD} 2.47)\end{array}$ & $21.276^{* *}$ & $\begin{array}{l}57.95 \\
(\mathrm{SD} 5.07)\end{array}$ & $7.601 * *$ \\
\hline Scenario-4 (MABP) & $\begin{array}{l}71.11 \\
(\mathrm{SD} 4.89)\end{array}$ & $\begin{array}{l}58.16 \\
(\mathrm{SD} 4.83)\end{array}$ & $7.180 * *$ & 65.15 (SD 7.46) & $2.33^{*}$ \\
\hline
\end{tabular}

${ }^{*} p<.05 ; * * p<.001 ;$ MABP $=$ Mean Arterial Blood Pressure 


\section{Study Limitations}

The primary limitation of the study is the absence of a novice control group (ie participants who received no internship experience). Instead, a highly experienced reference group was used to contrast levels of performance in the participants. The methods used in this study are not appropriate for use with extremely large samples. That said, the small sample size is a significant limitation of the study. We sought to limit this through the use of a professionally homogenous group, as was the case with the novices. The significant differences in performance seen between the novice and experienced groups materialized despite the greater professional variability seen in the experienced group. While not directly measured, several of the experienced participants were unfamiliar with simulation in general, and may well have performed better in an actual practice environment. Despite these minor limitations, the results of the study provide support for the assertions made therein, and offer a framework for future studies of a similar nature.

\section{Clinical implications}

The clinical implications of the paper are wide reaching. The paper provides important objective support for residency and internship programs in a way that is, to date, not seen in the literature. For clinical managers, the findings are important in that they both validate the efficacy of intensive training periods, as well as illustrating the limitations of such programs. That is, while novices improve markedly during such periods of instruction, they are novices, and thus, have limitations to their ability to perform in a timely and well-directed manner. This calls for the need to continue clinical supervision and teaching long after the residency or internship is completed.

\section{Conclusion}

The employment of novice nurses in critical care areas at entry to practice is often highly controversial. This study is the first to detail the degree to which a structured internship can facilitate changes in performance, at least as they relate to the titration of vasoactive medications. This study provided support for the notion that internship experiences, however short, provide for improvement in the performance of titration skills. While it is unclear if this finding is generalizable to other skills, we assert that this is likely. One must, however, consider the introduction of novices into critical care setting with caution, as even with the internship experience, they lagged well behind the experienced nurses with regards to their ability to effectively manage patients requiring vasoactive medication.

The study examined the effect associated with engagement in a structured internship. While novices improve significantly, they fail to achieve the level of clinical performance seen in experienced nurses. This is an important finding, in that it provides a means of framing the expected rate of progression of novices in a more quantifiable way. The study falls short of providing a means of predicting performance, however, it does provide important validation for changes in observable performance attributes in these nurses. Additionally, the study establishes aspects of the practice of experienced nurses that establish their superiority in practice. It is essential that studies such as the one reported here, continue to explore aspects of clinical performance in novices as a means of determining how to best address quality of care and safety issues in critical care and other highly complex clinical settings.

\section{References}

[1] Ellerbye, S., \& Regan, D. Responding to healthcare reform by addressing the Institute of Medicine report on the future of nursing. JONA's Healthcare Law, Ethics and Regulation, 2012; 14: 124-128. PMid:22677961 http://dx.doi.org/10.1097/NAQ.0b013e318258bfa7

[2] Hill, K. S. Nursing and the aging workforce: myths and reality, what do we really know? Nursing Clinics of North America. 2011; 46: 1-9. PMid:21320656 http://dx.doi.org/10.1016/j.cnur.2010.10.001

[3] Institute of Medicine. The Future of Nursing. Washington, D.C. National; Academy of Sciences, 2010.

[4] Hall, D., \& Marshall, R. Evaluation of a 16-week critical care internship program using a staff development program effectiveness evaluation tool. Journal of Nurses in Staff Development. 2006; 22: 134-143.

http://dx.doi.org/10.1097/00124645-200605000-00008 
[5] Salonen, A., Kaunonen, M., Meretoja, R., \& Tarkka, M. Competence profiles of recently registered nurses working in intensive and emergency settings. Journal of Nursing Management. 2007; 15: 792-800. PMid:17944604 http://dx.doi.org/10.1111/j.1365-2934.2007.00768.x

[6] Anderson, G., Hair, C., \& Todero, C. Nurse residency programs: An evidence based review of theory, process and outcomes. Journal of Professional Nursing. 2012; 28: 203-212. PMid:22818190 http://dx.doi.org/10.1016/j.profnurs.2011.11.020

[7] Rosenfeld, P., Smith, M., Lervolino, L., \& Bowar-Ferres. Nurse residency program: A 5-year evaluation from the participant's perspective. The Journal ofNursing Administration. 2004; 34: 188-194. http://dx.doi.org/10.1097/00005110-200404000-00006

[8] Beecroft, P., Kunzman, L., \& Krozek, C. RN internship: Outcomes of a one-year pilot program. JONA. 2001: $31: 575-582$. http://dx.doi.org/10.1097/00005110-200112000-00008

[9] Hillman, L., \& Foster, R. R. The impact of a nursing transitions programme on retention and cost savings. Journal of Nursing Management. 2012; 19: 51-56.

[10] Berube, M., Valiquette, M., Laplante, E., Lepage, I., Belmonte, Tanguay, A., et al. Nursing residency program: A solution to introduce new grads into critical care more safely while improving accessibility to services. Nursing Leadership. 2012; 25: 50-67. PMid:22469762 http://dx.doi.org/10.12927/cjnl.2012.22830

[11] Kramer, M., Halfer, D., Maguire, P., \& Schmalenberg, C. Impact of healthy work environments and multistage nurse residency programs on retention of newly licensed RNs. The Journal of Nursing Administration. 2012; 42: 148-159. PMid:22361872 http://dx.doi.org/10.1097/NNA.0b013e31824808e3

[12] Blanzola, C., Lindeman, R., \& King, M. L. Nurse internship pathway to clinical comfort, confidence, and competence. Journal of Nurses in Staff Development. 2004; 20: 27-37. http://dx.doi.org/10.1097/00124645-200401000-00006

[13] Wynd, C., \& Gotschall, W. Knowledge attainment, perceptions and professionalism in participants completing the didactic phase of the Army Reserve critical care nursing residency program. Military Medicine. 2000; 165: 243-251. PMid:10802992

[14] Altier, M., \& Kresk, C. Effects of a 1-year residency program on job satisfaction and retention of new graduate nurses. Journal for Nurses in Staff Development. 2006; 22: 70-77. PMid:16603904 http://dx.doi.org/10.1097/00124645-200603000-00006

[15] Anderson, T., Linden, L., Allen, M., \& Gibbs, E. New graduate RN work satisfaction after completing an interactive nurse residency. JONA. 2009; 39: 165-169. PMid:19359887 http://dx.doi.org/10.1097/NNA.0b013e31819c9cac

[16] Olson-Sitki, K., Wendler, M., \& Forbes, G. Evaluating the impact of a nurse residency program for newly graduated registered nurses. Journal of Nurses in Staff Development. 2012; 28: 156-162. PMid:22821016 http://dx.doi.org/10.1097/NND.0b013e31825dfb4c

[17] Cleary, M., Matheson, S., \& Happell, B. Evaluation of a transition to practice program for mental health nursing. Journal of Advanced Nursing. 2009; 65: 844-850. PMid:19243464 http://dx.doi.org/10.1111/j.1365-2648.2008.04943.x

[18] Kowalski, S., \& Cross, C. Preliminary outcomes of a local residency program for new graduate registered nurses. Journal of Nursing Management. 2010; 18: 96-104. PMid:20465735 http://dx.doi.org/10.1111/j.1365-2834.2009.01056.x

[19] Herdrich, R., \& Lindsay, A. Nurse residency programs: Redesigning the transition into practice. Journal for Nurses in Staff Development. 2006; 22: 55-62. PMid:16603901 http://dx.doi.org/10.1097/00124645-200603000-00003

[20] Krugman, M., Bretschneider, J., Horn, P., Kresk, C., Moutafis, R., \& Smith, M. The national post-baccalaureate graduate nurse residency program: A model for excellence in transition to practice. Journal for Nurses in Staff Development. 2006; 22; 196-205. PMid:16885686 http://dx.doi.org/10.1097/00124645-200607000-00008

[21] Ericsson, K.A., Whyte, J., \& Ward, P. Expert performance in nursing: Reviewing research on expertise in nursing within the framework of the expert- performance, Advances in Nursing Science. 2007; 30: 58-71. http://dx.doi.org/10.1097/00012272-200701000-00014

[22] Ericsson KA. Deliberate practice and the acquisition and maintenance of expert performance in medicine and related domains. Academic Medicine, 2004; 10:S1-S12.

[23] Whyte, J., Ward, P., \& Eccles, D. The relationship between knowledge and clinical performance in novice and experienced critical care nurses: An application of the Expert Performance Approach. Heart \& Lung. 2009; 38(6): 517-525. PMid:19944876 http://dx.doi.org/10.1016/j.hrtlng.2008.12.006

[24] Whyte, J., Hauber, R., Cormier, E., Grubbs, L. \& Ward, P. Clinical outcome measures in simulated task environments: Validation of the role of physiological and cognitive measures in assessing nursing performance. Applied Nursing Research. 2010: 23 , e1. PMid:20122502 http://dx.doi.org/10.1016/j.apnr.2009.02.004

[25] Hauber, R. P., Cormier, E., \& Whyte, J. An Exploration of the Relationship between Knowledge and Performance- related Variables in High Fidelity Simulation: designing instruction that promotes expertise in practice. Nursing Education Perspectives. 2010; 31: 242-246. PMid:20882866

[26] Whyte, J., Ward, P. Eccles, D., Harris, K., Nandagopal, K., \& Torof, J.. Nurses' immediate response to the fall of a hospitalized patient: A comparison of actions and cognitions of experienced and novice nurses. International Journal of Nursing Scholarship. 2013; 49: 1054-1063. PMid:22534491 http://dx.doi.org/10.1016/j.ijnurstu.2012.03.005 